\title{
NUMERICAL STUDY OF THE EFFECT OF CONCRETE COVER AND THE FRICTION OF STEEL CONCRETE INTERFACE Z. ZENASNI ${ }^{1}$, S. ATLATI ${ }^{2}$, M. HATERBOUCH ${ }^{1}$, K. HANNAWI $^{3}$, W.P. AGBODGAN ${ }^{3}$, K. NASRI ${ }^{2}$, R. ADDOU ${ }^{2}$, M. ZENASNI ${ }^{2}$
}

\author{
1. Equipe de Mécanique et Ingénierie Intégrée (M2I), ENSAM, Université Moulay Ismaïl, B.P. 15290 Al-Mansor, Meknès \\ 2. Equipe de Mécanique et Calcul Scientifique, BP 669, ENSA, 60000 OUJDA \\ 3. LGCGM, 20 Avenue des Buttes de Coësmes CS 70839, 35708 Rennes Cedex 7
}

\begin{abstract}
The work presented in this paper resume a numerical analysis of the concrete cover effect, on the resistance of the steel-concrete interface. The effect of friction on the interface behavior is also included. For this, a brief description of the experimental steps generally used for the characterization of the steel-concrete interface is presented. Also, the CDP model, Concrete Damage Plasticity, is illustrated. The results of the numerical simulation using the Abaqus code are presented with different diameters of coatings with and without friction.
\end{abstract}

Keywords: Steel-Concrete interface, CDP, adherence, finite element, Abaqus-explicit.

\section{Introduction}

Concrete is a heterogeneous material at different level of observation: from the nanometer (scale of the basic components of the cement paste) to the centimeter (representative scale of coarse aggregates).

In several domains of civil engineering, this material is increasingly used (building, tunnel, oil platforms, nuclear power plants, storage sites, ...), which can sometimes be exposed to severe conditions, fire, flood, earthquake .... For this, many models are developed considering the effect of different physicochemical, microstructural and geometrical parameters on the mechanical behavior of structures and influencing the stability of concrete. This stability depends on the cohesion at the interface between the concrete and the steel reinforcement, which can be evaluate by measuring the maximum value of pulling force and by studying behavior of the composite during the pull-out test.

In the following, we limit this work, at studying the effect of the size concrete cover and the effect of the friction on concrete steel behavior. This work is an initiation for a complete study considering the effect of high temperatures.

\section{Pull out test}

It is the most experimental test used to study the decohesion at the interface between the concrete and steel. Many studies carried out to describe the effect of high temperature on the interface between concrete and steel. We quote the experimental research carried out at INSA Rennes [1], on cylindrical specimens $(110 \mathrm{~mm}$ in diameter and $130 \mathrm{~mm}$ in height) reinforced with a steel bar (12 mm diameter). The bar is in the middle of the specimen and anchored on his half height $(65 \mathrm{~mm})$ figure 1.

Tensile tests are carried out on the cylindrical test pieces using a traction machine. This machine "TESTOMETIC" is driven at speed of $0.5 \mathrm{~mm} / \mathrm{min}$ by a computer with WinTEST analysis software

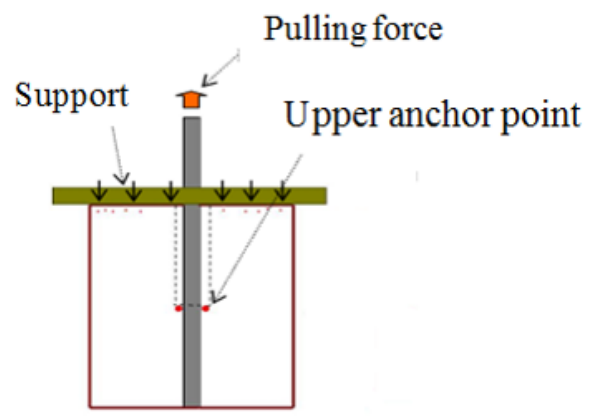

Figure 1 : Pull out test

\section{Damage models for concrete}

Several studies have been developed by different authors, to evaluate the mechanical behavior of the steelconcrete interface.

We quote the work of Mazars [2], and Lubliner and al. [3] known as the Concrete Damage Plasticity 'CDP' model. We will define in the following the CDP model, implemented in the Abaqus code.

\subsection{Concrete Damage Plasticity model}

The Concrete Damage Plasticity 'CDP' has already shown its effectiveness in different numerical studies of concrete behavior, like Jankowiak and al [4], Ghosh and al. [5] works.

This model was proposed by Lubliner and al. [3] and later improved by Lee and Fenves [6]. The constitutive relationship between stress and strain through damage is based on the concept of damaged modulus of elasticity. It is expressed by:

$\boldsymbol{\sigma}=(\mathbf{1}-d) D_{0}^{e l}:\left(\boldsymbol{\varepsilon}-\boldsymbol{\varepsilon}^{\mathbf{p l}}\right)=D^{e l}:\left(\boldsymbol{\varepsilon}-\boldsymbol{\varepsilon}^{\mathbf{p l}}\right)$

$\boldsymbol{\sigma}$ is the Cauchy stress, $\boldsymbol{\varepsilon}$ is the deformation tensor, $\mathrm{d}$ is the damage variable, $D_{0}^{e l}$ the initial undamaged elastic stiffness of the material, and $\boldsymbol{D}^{e l}=(\mathbf{1}-d) \boldsymbol{D}_{\mathbf{0}}^{e l}$ is the elastic stiffness damaged The tensor of the effective stresses is defined by: 


$$
\widetilde{\boldsymbol{\sigma}}=D_{0}^{e l}:\left(\varepsilon-\varepsilon^{\mathrm{pl}}\right)
$$

The Cauchy stress tensor is connected to the effective stress tensor through the damage parameter $(1-d)$ by the following relation:

$\boldsymbol{\sigma}=(\mathbf{1}-d) \widetilde{\boldsymbol{\sigma}}$

The compression and tensile damage states are independently characterized by two variables $\widetilde{\varepsilon_{c}^{p l}}$ and $\widetilde{\varepsilon_{t}^{p l}}$ which are respectively the equivalent plastic deformations in compression and traction. The parameters which the 'CDP' model is based are the angle of expansion $\emptyset$, the eccentricity of the potential plastic surface e, the parameter $f$ which represents the ratio between the compressive strength of the concrete under a bi-axial loading state and the compressive concrete strength, the parameter $\mathrm{k}$ which has been introduced by Drucker-Prager [7], it has an influence on the surface of the fracture and finally the viscoplasticity parameter $\mu$ acts directly on the stressstrain relationship.

In addition to the parameters mentioned above, the insertion of the data concerning the compression damage parameter $d_{c}$ and the tensile damage parameter $d_{t}$ is essential to analyze the damage of the model in question, either in tension or in compression. The extraction of these values is based on the experimental curves, representing the stress-strain relationship in both the tensile and compressive cases, as shown in figure 2 .

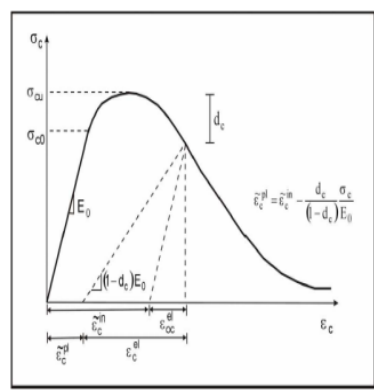

(a) compression

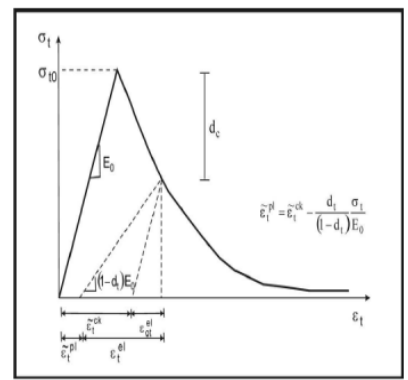

(b) tension

Figure 2 : Concrete mechanical behavior

\subsection{Steel-Concrete Interface}

The interface modeling on Abaqus uses a MASTERSLAVE contact. The principle of this code considers that the nodes of the SLAVE surface cannot penetrate the segments that form the MASTER surface, as represented in Figure 3.

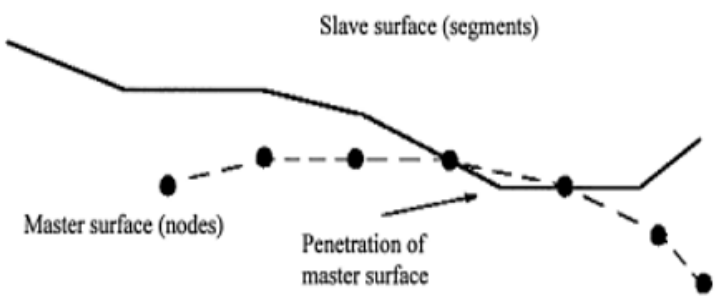

Figure 3: MASTER surface and SLAVE surface, [8]

In the case of materials of our interface, the steel is considered rigid and the concrete is considered deformable. The surface of the steel will represent the master surface and the surface of the concrete will represent the slave surface.

\section{Geometry and finite element model}

In this work, we represented the pull out test on a specimen formed by the two materials steel and concrete. figure 4 shows the dimensions of the model $(L=23.8$ $\mathrm{mm}, h=50 \mathrm{~mm}$ et $d=6 \mathrm{~mm})$ and the applied loading (V $=0.5 \mathrm{~mm} / \mathrm{min}$ ).

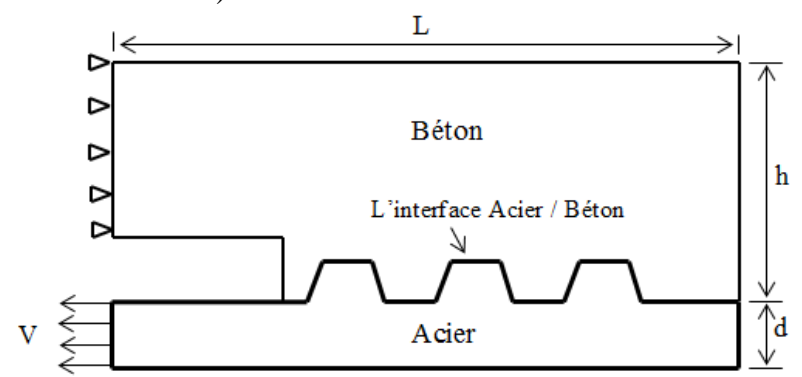

Figure 4: Steel-concrete interface model, [1]

To model the behavior of concrete at the Concrete-Steel interface under the effect of the applied loading, we used the CDP model.

This choice is justified by the effectiveness in the processing of numerical computation. The specimen was modeled by the type of elements CPE4R: "4-Node bilinear Plane strain quadrilateral Reduced integration". A mesh convergence study was carried out in advance to identify the most appropriate mesh for our study.

\section{Results and discussion}

In order to understand the effect of the concrete cover on the steel-concrete bond, we varied the thickness of the concrete cover $\mathrm{h}$, and we calculated the pulling force as a function of the displacement. Figure 5 illustrates the pulling force displacement relationship for different values of $h$. 
The force stabilizes for the $30 \mathrm{~mm}, 35 \mathrm{~mm}, 40 \mathrm{~mm}$ and $50 \mathrm{~mm}$ concrete cover, with a maximum force level of $16400 \mathrm{~N}$ for the $40 \mathrm{~mm}$ coating and which corresponds to a displacement of about $0.42 \mathrm{~mm}$. For $\mathrm{h}$ smaller than 30 $\mathrm{mm}$ there is a weak resistance of the steel-concrete interface. The level of the force decreases more and more as the concrete cover decreases to reach a maximum strength level of about $120 \mathrm{~N}$ for the $10 \mathrm{~mm}$.

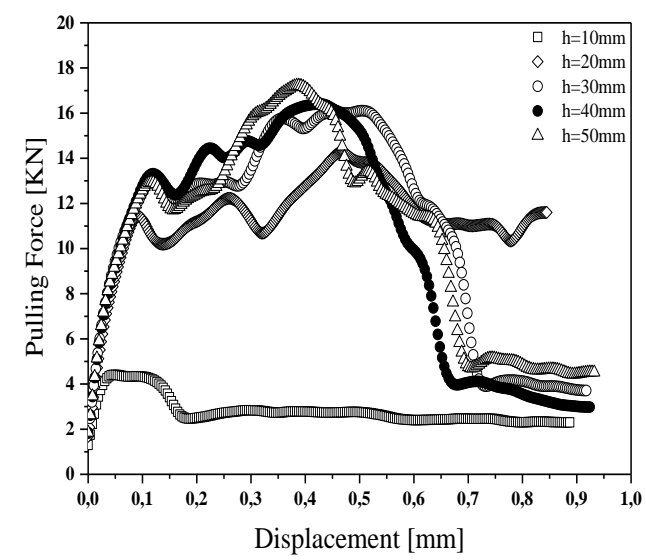

Figure 5: Force-displacement relationship for different concrete cover.

For a more meaningful representation of the SteelConcrete interface resistance, we represent stress of adhesion $\left(\tau_{\mathrm{a}}=\frac{F}{\pi \cdot \varphi \cdot l a}\right)$-displacement relationship $\delta$, where $F$ is the pulling force, $\varphi=12 \mathrm{~mm}$ the diameter of the steel and $l_{a}=23.8 \mathrm{~mm}$ the adhesion length. The maximum stress of adhesion is reached in the case of $\mathrm{h}=$ $40 \mathrm{~mm}$ for $\delta=0.428 \mathrm{~mm}$, it is about $18.2 \mathrm{MPa}$.

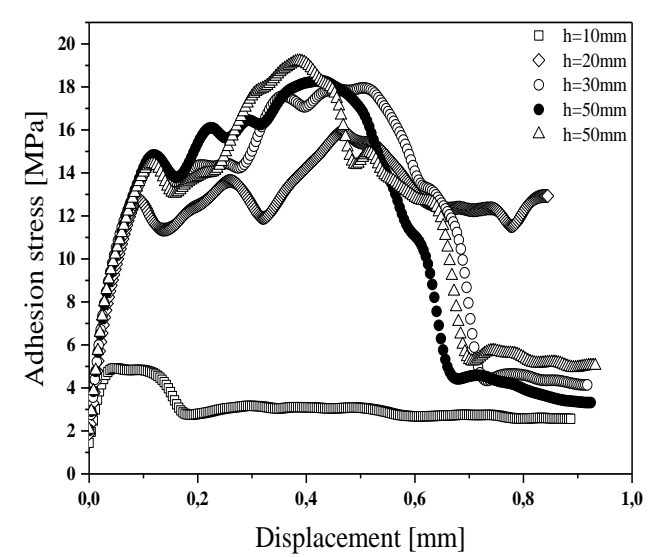

Figure 6: Stress-displacement relationship for different concrete cover.

The effect of friction in this work is analyzed by studying two cases. For a $40 \mathrm{~mm}$ concrete cover, the first case of friction is the "Penalty" type, where we have to insert the coefficient of friction in question. The second case is the "Static-Kinetic Exponential Decay" type, which assumes that the coefficient of friction decreases exponentially from the value of static friction to the value of kinetic friction. The appearance shown in figure 7 below, reflects the evolution of the pulling force as a function of displacement, considering the two types of friction in question. The friction type 'penalty', in our case, shows an insignificant result.
Indeed, the level of the maximum force reached in this case does not exceed $8 \mathrm{kN}$ and the drop level of this force is about $0.25 \mathrm{~mm}$ remains far from reality.

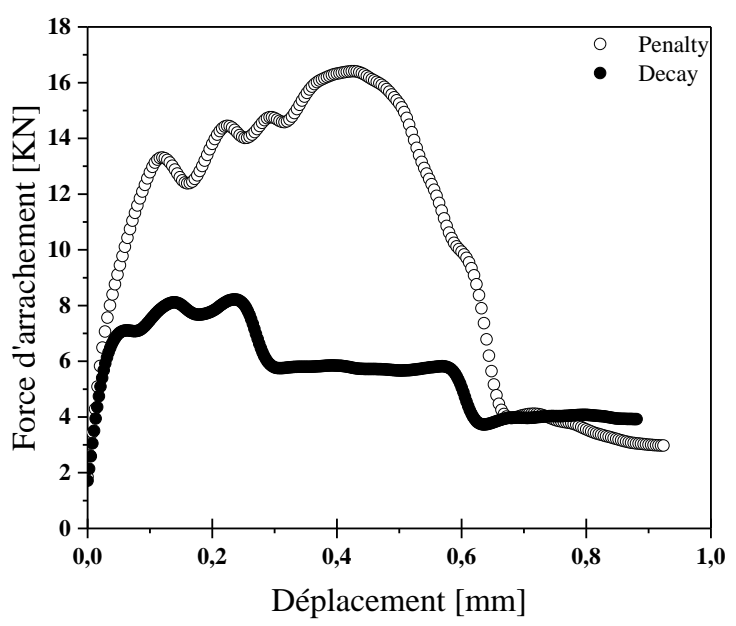

Figure 7 : Effect of friction on pulling force, coating $40 \mathrm{~mm}$

\section{Conclusion}

As a first step in characterizing the concrete steel interface, we have succeeded in numerically optimizing the cover concrete around the steel for perfect adhesion. Also, we studied numerically the effect of friction on this adhesion. The optimization of the calculation time was part of this work. The mechanical results agree with the forecasts, pending the second step we will consider the effect of the history of the temperature on the concrete steel interface.

\section{References}

[1] Nguyen N. H., Dégradation du béton armé sous actions sévères : Etude du comportement résiduel de l'adhérence à l'aide de la technique d'émission acoustique, Thèse de doctorat, INSA Rennes, 2014.

[2] Mazars, Application de la mécanique de l'endommagement au comportement non linéaire et à la rupture, thèse de doctorat, Université Paris VI, (1984).

[3] Lubliner J., Oliver J., Oller S., A plastic-damage model for concrete, International Journal of Solids and Structures, (1989), 299-329.

[4] Tjankowiak, T. Lodygowski, Identifcation of parameters of concrete damage plasticity constitutive model, FOUNDATIONS OF CIVILAND ENVIRON MENTALENGINEERING, vol 6, (2005), 53-69.

[5]A Ghosh Lee J., Fenves G.L. Plastic-damage model for cyclic loading of concrete structures, Journal of Engineering Mechanics., B.Sc. Engg. (Civil), BUET, Bangladesh, (2000)

[6] Lee J., Fenves G.L, Plastic-damage model for cyclic loading of concrete structures, Journal of Engineering Mechanics, (1998), 892-900

[7] Drucker, D.C., Prager, W. Soil mechanics and plastic analysis or limit design. Quart. Appl. Math. 10, 157-165, 1952.

[8] Abaqus Analysis User's Guide 6.14. 